\title{
Encapsulation of fish oil in protein aerogel micro-particles
}

\section{Selmer, llka}

2019-11

Selmer , I , Karnetzke , J , Kleemann , C , Lehtonen, M , Mikkonen , K S , Kulozik , U \&

Smirnova , I 2019 , ' Encapsulation of fish oil in protein aerogel micro-particles ' , Journal of Food Engineering , vol. 260 , pp. 1-11 . https://doi.org/10.1016/j.jfoodeng.2019.04.016

http://hdl.handle.net/10138/314739

https://doi.org/10.1016/j.jfoodeng.2019.04.016

cc_by_nc_nd

acceptedVersion

Downloaded from Helda, University of Helsinki institutional repository.

This is an electronic reprint of the original article.

This reprint may differ from the original in pagination and typographic detail.

Please cite the original version. 


\section{Accepted Manuscript}

Encapsulation of fish oil in protein aerogel micro-particles

Ilka Selmer, Julia Karnetzke, Christian Kleemann, Mari Lehtonen, Kirsi S. Mikkonen, Ulrich Kulozik, Irina Smirnova

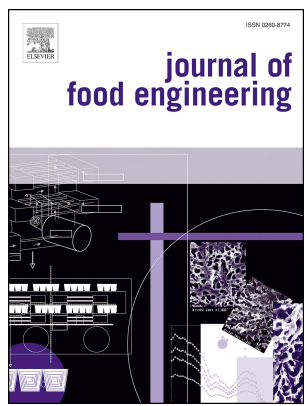

PII: S0260-8774(19)30174-8

DOI: https://doi.org/10.1016/j.jfoodeng.2019.04.016

Reference: JFOE 9582

To appear in: Journal of Food Engineering

Received Date: 11 January 2019

Revised Date: 22 March 2019

Accepted Date: 24 April 2019

Please cite this article as: Selmer, I., Karnetzke, J., Kleemann, C., Lehtonen, M., Mikkonen, K.S., Kulozik, U., Smirnova, I., Encapsulation of fish oil in protein aerogel micro-particles, Journal of Food Engineering (2019), doi: https://doi.org/10.1016/j.jfoodeng.2019.04.016.

This is a PDF file of an unedited manuscript that has been accepted for publication. As a service to our customers we are providing this early version of the manuscript. The manuscript will undergo copyediting, typesetting, and review of the resulting proof before it is published in its final form. Please note that during the production process errors may be discovered which could affect the content, and all legal disclaimers that apply to the journal pertain. 
Protein aerogel micro particles mixed with fish oil (state of the art) impregnated with fish oil from supercritical $\mathrm{CO}_{2}$

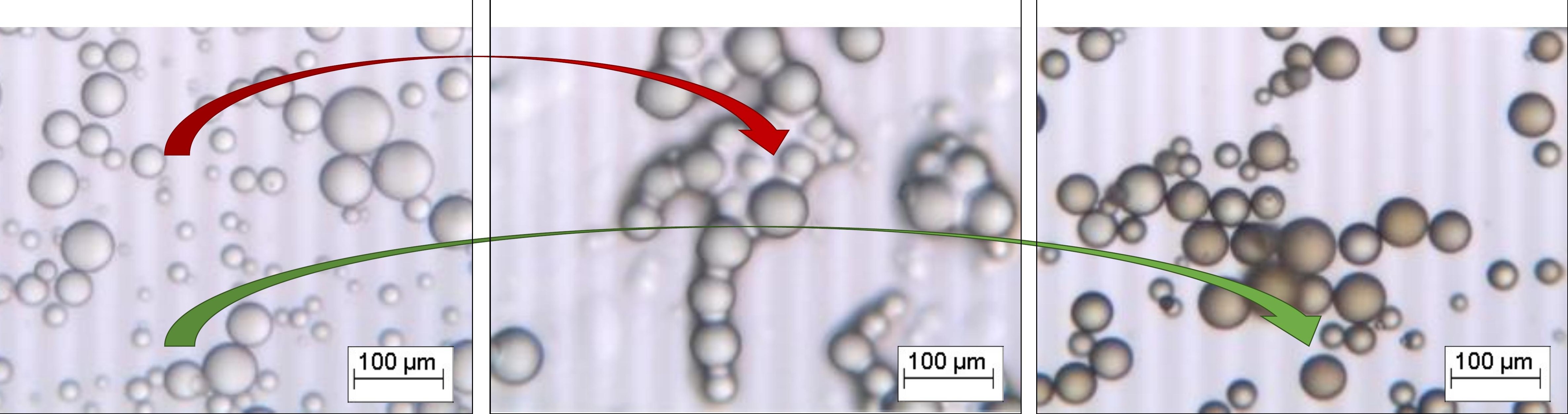




\section{Encapsulation of fish oil in protein aerogel micro-particles}

2 Ilka Selmer ${ }^{* 1}$, Julia Karnetzke ${ }^{1}$, Christian Kleemann $^{2}$, Mari Lehtonen $^{3}$, Kirsi S. Mikkonen ${ }^{3,4}$,

3 Ulrich Kulozik², Irina Smirnova ${ }^{1}$

41 Institute for Thermal Separation Processes, Hamburg University of Technology,

5 Eißendorfer Straße 38, 21073 Hamburg (Germany), e-mail: ilka.selmer@tuhh.de,

$6 \quad$ irina.smirnova@tuhh.de

72 Technical University of Munich, Chair of Food and Bioprocess Engineering,

8 Weihenstephaner Berg 1, 85354 Freising (Germany), e-mail: christian.kleemann@tum.de,

9 ulrich.kulozik@tum.de

${ }^{3}$ Department of Food and Nutrition, University of Helsinki, P.O. Box 66, FIN-00014 Helsinki (Finland), mari.lehtonen@env.fi, kirsi.s.mikkonen@helsinki.fi

${ }^{4}$ Helsinki Institute of Sustainability Science, Faculty of Agriculture and Forestry, University of Helsinki, Finland

* corresponding author: Ilka Selmer

\section{Introduction}

One objective of the food industry is to increase the shelf-life of sensitive nutrients and to control their release in the human digestive system. Encapsulation enables the protection of sensitive ingredients from adverse conditions like oxygen, moisture, temperature or light and offers the possibility to mask undesirable tastes and odors of bioactive functional food additives (Tavares et al., 2014). One way of encapsulation is the concept of aerogel manufacture and loading. Aerogels can be defined as dry, open mesoporous, coherent networks of inorganic or organic solid material formed by gelation and subsequent supercritical drying. A decisive point of difference of aerogels in comparison to other drying methods is the retention of shape and inner structure during supercritical drying. The inner specific surface area of aerogels is therefore extremely high and available for adsorption, while, in addition, the high inner porosity is finely structured offering a large inner volume for capillary condensation of sensitive material. The filled pores of the aerogel structure should protect sensitive substances from contact with air and oxidation. Additionally, the mesoporous structure itself acts as transport residence for air and oxidation products.

Aerogels based on natural biopolymers, like polysaccharides or proteins, are novel carrier materials for pharmaceutical products due to their biocompatibility and biodegradability 
(Mehling et al., 2009). Additionally, they are safe, edible, renewable and sustainable and thus also applicable in food systems (Mikkonen et al., 2013). Their open mesoporous structure results in extraordinary properties like large specific BET (Brunauer-Emmet-Teller)-surface areas and high porosities building the basis for a carrier material (Mikkonen et al., 2013). Aerogels made from natural polymers, mainly from polysaccharides in form of microparticles, were investigated in several studies as transport matrices for pharmaceuticals (Alnaief et al., 2011; Baldino et al., 2016; Betz et al., 2012; Cicco et al., 2016; GarcíaGonzález et al., 2011; García-González et al., 2015; Gonçalves et al., 2016; Haimer et al., 2010; Lovskaya et al., 2015; Maleki et al., 2016; Marin et al., 2014; Mehling et al., 2009; Mustapa et al., 2018; Obaidat et al., 2018; Salgado et al., 2017; Stergar and Maver, 2016; Ulker and Erkey, 2014; Veres et al., 2018; Zhao et al., 2018). For food applications, aerogel micro-particles are promising since their integration into food matrices does not change the food structure significantly. The consumer acceptance of food additives encapsulated in aerogel micro-particles is assumed to be higher than of those being encapsulated in aerogel monoliths.

In principal, the production of biopolymer-based aerogels consists of three steps: Gel formation in aqueous solution, solvent exchange from water to an organic solvent (e.g. ethanol) followed by the supercritical $\mathrm{CO}_{2}$-drying of the gel matrix. The integration of a valuable compound into an aerogel matrix can be conducted by an addition in different aerogel production steps depending on the valuable compound's affinity to the used solvents (water, organic solvent, supercritical $\mathrm{CO}_{2}$ ) (Comin et al., 2012; Maleki et al., 2016; Ulker and Erkey, 2014):

a) before gelation,

b) during solvent exchange,

c) during supercritical drying

d) after supercritical drying.

The addition after gel formation (possibilities b) - d)) is interesting for the food industry since a separate production of the transport matrix from its loading enables gelation at high temperatures or extreme $\mathrm{pH}$-values without degradation of the sensitive valuable compound. After loading the matrix, an additional coating layer can be applied onto the aerogels as additional protection (Alnaief et al., 2010; Alnaief et al., 2012; Goslinska et al., 2019; Kleemann et al., 2018). The interest in biopolymer-based aerogels and cryogels (obtained by freeze-drying) as transport matrices for food applications becomes obvious when considering the increasing number of studies in the last few years covering this topic (Ahmadi et al., 2016; Comin et al., 2012; Haimer et al., 2010; Marco and Reverchon, 2017; Pantić et al., 2016b; Pantić et al., 2016a). These studies show that biopolymer-based aerogels can be 
loaded with significant amounts of oil or vitamin by various loading techniques. Mostly, polysaccharides were used as matrix material in these studies or conventional freeze drying was applied to convert a hydrogel into a dried matrix. This study uses natural proteins as matrix material in combination with supercritical $\mathrm{CO}_{2}$-drying of the protein gel matrix. Such monolithic protein-based aerogels were tested already in first studies as carrier matrices for drug release (Betz et al., 2012; Marin et al., 2014) but not for food applications. In previous studies we developed protein aerogels in the form of micro-particles consisting of natural proteins obtained from milk and egg white designed for food systems (Betz et al., 2012; Kleemann et al., 2018; Selmer et al., 2015). Additionally, we successfully tested the coating of these protein-based aerogel micro-particles (Goslinska et al., 2019). In the present paper, we evaluate the loading of the previously developed protein aerogel particles made of structurally different protein materials with exemplary core materials of interest for application in food systems. Aerogel micro-particles produced from the protein sources whey protein isolate (WPI), sodium caseinate (NaCas) and egg white protein (EWP) were utilized. These proteins have different molecular structures, different reactive sites for crosslinking and the mechanisms of gel formation are partially different. Therefore, the precursor hydrogels are different as well as their resulting supercritically dried aerogel structures (Kleemann et al., 2018; Selmer et al., 2015). We expect that the different aerogel structures show different loading capacities. Fish oil was selected as exemplary model additive. The purpose was to protect it against oxidation. Fish oil is rich in essential unsaturated $\omega$-3-fatty acids, which have positive effects on the human health, but are sensitive to oxidation. The oxidation products of the $\omega$-3-fatty acids produce rancid odors and flavors (Miyashita et al., 2018). The possibilities of protecting the core material against oxidation and masking potential off-flavors make fish oil encapsulation technologies highly interesting for the food industry. (Bakry et al., 2016; Encina et al., 2016). The aim of this study is to achieve high specific loadings of the chosen biological functional model substances onto the aerogel particles using different loading techniques to evaluate more broadly the potential of protein aerogels as a carrier material in food systems.

\section{Materials and methods}

\subsection{Materials}

Pasteurized egg white was provided from Ovobest Eiprodukte $\mathrm{GmbH}$ \& Co. KG (Neuenkirchen-Vörden, Germany). Whey protein isolate with a protein content of $94 \%(w / w)$ was purchased from Davisco Foods International Inc. (Eden Prairie, USA). Sodium caseinate N94 with a protein content of $90 \%(\mathrm{w} / \mathrm{w})$ was obtained from Molkereigesellschaft Lauingen $\mathrm{mbH}$ (Lauingen, Germany). Activa MP Transglutaminase formulation with a specified activity of $100 \mathrm{U} / \mathrm{g}$ powder was provided by Ajinomoto Foods Europe S.A.S. (Paris, France). Pure 
Sunflower oil was purchased from a local store. Polyglycerin-Polyricinoleat (PGPR) 4150 was provided by Palsgaard (Juelsminde, Denmark) and fish oil from Fresenius Kabi AG (Bad Homburg v. d. Höhe, Germany). Marine Oil FAME Mix cat.: 35066 from Restek GmbH (Bad Homburg v. d. Höhe, Germany) was utilized as standard for fatty acid methyl esters. Hexane (> 95\% purity) was obtained from Merck KGaA (Darmstadt, Germany) and food grade carbon dioxide from Praxair Technology, Inc. (Düsseldorf, Germany). All other chemicals were purchased from Carl Roth (Karlsruhe, Germany) or Merck KGaA (Darmstadt, Germany) and were of analytical grade.

\subsection{Methods}

\subsubsection{Protein aerogel micro-particles}

115

The utilized spherical protein aerogel micro-particles were produced via emulsion gelation method followed by supercritical drying according to KLEEMANN ET AL. (Kleemann et al., 2018). Two sorts of WPI-aerogel particles with different pore structures and mean particle sizes were produced: During preparation of the small hydrogel particles deionized water was utilized as washing media (Kleemann et al., 2018) in case of WPI I particles and $10 \mathrm{mM}$ $\mathrm{CaCl}_{2}$-solution was utilized in case of WPI II particles. Further, EWP- and NaCas-aerogel particles were tested. The aerogel particles' appearance under the electron microscope is shown in Figure 1. Their properties are presented in Table 1.

Table 1: Properties of the protein aerogel particles determined according to the methods described in SeLmer ET AL. (Selmer et al., 2015).

\begin{tabular}{lccccc}
\hline \multicolumn{1}{c}{ Property } & Unit & WPI I & WPI II & EWP & NaCas \\
\hline BET-surface area & $\mathrm{m}^{2} / \mathrm{g}$ & $354 \pm 37$ & $154 \pm 15$ & $232 \pm 12$ & $48 \pm 5$ \\
Pore volume (BJH) & $\mathrm{cm}^{3} / \mathrm{g}$ & $1.55 \pm 0.11$ & $0.33 \pm 0.13$ & $2.28 \pm 0.18$ & $0.28 \pm 0.13$ \\
Mean pore diameter & $\mathrm{nm}$ & 14.0 & 7.1 & 41.7 & 13.4 \\
Mean particle size & $\mu \mathrm{m}$ & $66.6 \pm 1.6$ & $47.3 \pm 1.1$ & $32.7 \pm 0.4$ & $40.9 \pm 0.0$ \\
Bulk density $^{* *}$ & $\mathrm{~kg} / \mathrm{m}^{3}$ & $241 \pm 3$ & - & $179 \pm 2$ & $443 \pm 1$
\end{tabular}

${ }^{*}$ The pore and particle size distributions are presented in the supplementary information. The particle size distribution (of 7,000 to 10,000 particles per sample) was measured twice using a Camsizer XT with X-Jet module (Retsch GmbH, Haan, Germany). ${ }^{* *}$ The bulk density was calculated from measured weight $( \pm 0.0001 \mathrm{~g})$ and volume (adjusted to $1 \mathrm{~mL}$ after three taps) of the aerogel particles (triplicate measurements).

2.2.2. Static adsorption of fish oil from supercritical $\mathrm{CO}_{2}$ on protein aerogel micro-particles 
Two different sets of static adsorption experiments were conducted. The first set of static adsorption experiments was used to investigate the thermodynamic equilibrium. Fish oil saturated supercritical $\mathrm{CO}_{2}$ was utilized in all experiments. The thermodynamic equilibrium was measured by simultaneous triple measurements in three (of the four) different highpressure autoclaves being identical in construction (Figure 2). $3 \mathrm{~mL}$ of fish oil were placed with a syringe at the bottom of each of the $40 \mathrm{~mL}$ autoclaves. $0.6 \mathrm{~g}$ of the WPI- or NaCasaerogel particles or rather $0.3 \mathrm{~g}$ of the EWP-aerogel particles were packed in a filter paper which was rolled up and clamped in each autoclave above the fish oil without any contact. The autoclaves were closed and preheated. The $\mathrm{CO}_{2}$ was delivered from a $\mathrm{CO}_{2}$ tank, liquified by cooling and afterwards pumped to the desired pressure. Subsequently, the compressed $\mathrm{CO}_{2}$ was heated in a separate storage tank to the desired temperature and thus brought into supercritical conditions. The autoclaves were pressurized simultaneously by thus conditioned $\mathrm{CO}_{2}$ using a pressurization rate of approx. $1.5 \mathrm{MPa} / \mathrm{min}$ via the control valve 15 (Figure 2). Afterwards, the inlet valve of each autoclave was closed to conduct separated experiments. The starting time for the adsorption process was taken when constant temperature and pressure were reached. Pressures between 10 and $18 \mathrm{MPa}$ and temperatures in the range of 35 to $60 \mathrm{C}$ were inves tigated. At the end of the adsorption process, the autoclaves were simultaneously depressurized via the heated control valve 16 (Figure 2) using a depressurization rate equal or smaller than $-0.1 \mathrm{MPa} / \mathrm{min}$ to avoid precipitation of the solubilized fish oil in the depressurized $\mathrm{CO}_{2}$. The fish oil loaded aerogel particles were stored still packed in filter paper in a desiccator for further analysis.

The second set of static adsorption experiments was needed to load enough aerogel particles for consecutive fish oil oxidation measurements. It was conducted at the system conditions, where the highest fish oil loading could be achieved during the first set of experiments. A $1 \mathrm{~L}$ high pressure autoclave was used to load $12 \mathrm{~g}$ of aerogel particles via adsorption of fish oil from supercritical $\mathrm{CO}_{2}$. Therefore, $16 \mathrm{~g}$ fish oil were placed with a syringe at the bottom of the preheated autoclave $\left(40^{\circ} \mathrm{C}\right)$. Afterwards, a metal lattice was placed above the fish oil. $4 \mathrm{~g}$ of each aerogel particle source (WPI, EWP and NaCas) were put into filter papers and placed onto the metal lattice without any contact to the fish oil. The autoclave was closed and pressurized by $\mathrm{CO}_{2}$ up to $18 \mathrm{MPa}$. After $72 \mathrm{~h}$ the depressurization (- $\mathrm{dp} / \mathrm{dt}<0.1 \mathrm{MPa} / \mathrm{min}$ ) was started. The loading experiment in the $1 \mathrm{~L}$ autoclave was carried out twice.

\subsubsection{Analysis of fish oil loading}

The complete sample amount (adsorption in $40 \mathrm{~mL}$ autoclaves) or $0.6 \mathrm{~g}$ (adsorption in $1 \mathrm{~L}$ autoclave) of the loaded aerogel particles were placed in $30 \mathrm{~mL}$ hexane in a $50 \mathrm{~mL}$ centrifuge tube, sonicated for $15 \mathrm{~min}$ and centrifuged (800 rcf) for $15 \mathrm{~min} .20 \mathrm{~mL}$ of the fish 
oil hexane mixture was transferred to a round-bottomed flask (volume $=250 \mathrm{~mL}$ ). $20 \mathrm{~mL}$ fresh hexane was added to the centrifuge tube, sonicated and centrifuged. Again $20 \mathrm{~mL}$ of the fish oil hexane mixture was transferred to the same round-bottomed flask. This extraction step was repeated four times resulting in $80 \mathrm{~mL}$ fish oil hexane mixture in the roundbottomed flask. The hexane was evaporated afterwards in a rotating evaporator at $55^{\circ} \mathrm{C}$ and $0.02 \mathrm{MPa}$. The fish oil amount in the round-bottomed flask was determined gravimetrically. Duplicate measurements were conducted for the samples being processed in the $1 \mathrm{~L}$ autoclave.

\subsubsection{Analysis of fish oil}

Lipid composition of the fish oil was determined as follows: 50 to $100 \mathrm{mg}$ fish oil was weighed in a $1 \mathrm{~mL}$-volumetric flask $( \pm 1 \mathrm{mg})$ and dissolved in chloroform. $150 \mu \mathrm{L}$ of this solution and $150 \mu \mathrm{L}$ of $\mathrm{N}$-methyl-N-trimethylsilylheptafluorobutyramide (MSHFBA) were transferred to a GC vial where active hydrogen groups were derivatized to form volatile trimethylsilylderivatives. Therefore, the sample was placed for one hour at $60 \mathrm{C}$ in an oven before being analyzed by gas chromatography. The utilized GC-FID method is described in Table 2.

Table 2: Settings GC/FID system for fish oil fat analysis.

\begin{tabular}{|c|c|c|c|}
\hline Instrument: & \multicolumn{3}{|c|}{ Agilent GC7890B with FID, autosampler 7683} \\
\hline Column: & \multicolumn{3}{|c|}{$\begin{array}{c}\text { DB 17HT, } 30 \mathrm{~m} \times 0.15 \mathrm{~mm} \text { I.D. } \times 0.32 \mu \mathrm{m} \text { from Agilent } \\
\text { Technologies, Inc. (Santa Clara, USA) }\end{array}$} \\
\hline Carrier gas: & \multicolumn{3}{|c|}{ Helium (99.999\% purity) } \\
\hline \multirow[t]{5}{*}{ Temperature program: } & Temperature $\left({ }^{\circ} \mathrm{C}\right)$ & Time (min.) & Rate ( $\left.{ }^{\circ} \mathrm{C} / \mathrm{min}\right)$ \\
\hline & 50 & 1 & 13 \\
\hline & 240 & 0 & 15 \\
\hline & 310 & 0 & 40 \\
\hline & 348 & 38 & - \\
\hline Gas setting: & $\begin{array}{l}\text { carrier gas: } \\
\mathrm{H}_{2}=40 \mathrm{~mL} / \mathrm{min} \text {, }\end{array}$ & $\begin{array}{l}\text { MPa; detecto } \\
\text { gas air }=450 \mathrm{n} \\
e=45 \mathrm{~mL} / \mathrm{min}\end{array}$ & $\begin{array}{l}\text { ustion gas } \\
\text { makeup gas }\end{array}$ \\
\hline Injection conditions: & & , split ratio 1: & \\
\hline Injection volume: & & $1 \mu \mathrm{L}$ & \\
\hline Detector temperature: & & $350^{\circ} \mathrm{C}$ & \\
\hline
\end{tabular}

184 The resulting chromatogram was evaluated by comparison with standard chromatograms. 185 Therefore, stock solutions of known lipid components (approx. $2 \mathrm{~g} / \mathrm{L}$ free fatty acids (FFA) and monoglycerides, 2-4 g/L diglycerides and 4-6 g/L triglycerides) or cholesterol were dissolved in chloroform and subsequently derivatized and analyzed as described above. The results are reported as cumulated peak areas of the corresponding lipid component relative to the total cumulated peak areas. 
The determination of the fish oil fatty acid composition was conducted according to DIN EN

191

192

193

194

195

196

197

198

199

200

201

202

203

204

205

206

207

208

209

210

211

212

213

214 ISO 12966-2 (DIN-Normenausschuss Lebensmittel und landwirtschaftliche Produkte, 2017) via transesterification of the fish oil into the corresponding fatty acid methyl esters (FAME) and subsequent gas chromatographic (GC) analysis (Simon and Stahl, 2016).

\subsubsection{Oxidation measurements of fish oil loaded particles}

The volatile compounds of the fish oil loaded aerogel particles were analyzed using static headspace gas chromatography coupled to flame ionization detection (SHS-GC-FID). The analysis was conducted directly after the adsorption experiments. First, the fish oil loaded aerogel particles were transferred into $20 \mathrm{~mL}$ vials which were sealed hermetically. The vials were heated up to $100 \mathrm{C}$ for one hour in the headsp ace system (TurboMatrix HS40 Trap, PerkinEImer, Inc., Waltham, USA) to equilibrate the volatile compounds of the sample and the corresponding headspace. Afterwards, a dosing needle was inserted into the vial and the pressure was raised to $0.1379 \mathrm{MPa}$ for one minute to transfer the headspace to the GC-FID system. The settings of the utilized GC method are presented in Table 3. The measurements were repeated twice for each sample.

Table 3: Settings GC/FID system for the determination of the volatile compounds.

\begin{tabular}{|c|c|c|c|}
\hline Instrument: & \multicolumn{3}{|c|}{ Agilent GC7890A with FID } \\
\hline Column: & \multicolumn{3}{|c|}{$\begin{array}{c}\text { Stabilwax-DA, } 60 \mathrm{~m} \times 0.32 \mathrm{~mm} \text { I.D. } \times 1.00 \mu \mathrm{m} \text { from Restek GmbH } \\
\text { (Bad Homburg v. d. Höhe, Germany) }\end{array}$} \\
\hline Carrier gas: & \multicolumn{3}{|c|}{ Helium (99.999\% purity) } \\
\hline \multirow[t]{3}{*}{ Temperature program: } & Temperature $\left({ }^{\circ} \mathrm{C}\right)$ & Time (min.) & $\mathrm{R}$ ate $\left({ }^{\mathrm{C}} \mathrm{C} / \mathrm{min}\right)$ \\
\hline & & 1 & 10 \\
\hline & 210 & 12 & - \\
\hline Gas setting: & \multicolumn{3}{|c|}{$\begin{array}{l}\text { carrier gas: } \mathrm{He}=0.08 \mathrm{MPa} \text {; detector: combustion gas } \mathrm{H}_{2}=40 \mathrm{~mL} / \mathrm{min} \text {, } \\
\text { oxidant gas air }=400 \mathrm{~mL} / \mathrm{min} \text {, makeup gas } \mathrm{He}=45 \mathrm{~mL} / \mathrm{min}\end{array}$} \\
\hline Injection temperature: & \multicolumn{3}{|c|}{$150^{\circ} \mathrm{C}$} \\
\hline Detector temperature: & \multicolumn{3}{|c|}{$250^{\circ} \mathrm{C}$} \\
\hline
\end{tabular}

The resulting chromatograms were compared with standard substances to identify the detected compounds using the measured retention times. Hereby the focus was on the substances identified by LEE ET AL. as odor intense oxidation products of $\omega$-3-fatty acids (Lee et al., 2003).

To get more detailed information about the composition of the volatile compounds and the oxidative status of the fish oil, loaded protein aerogel particles were evaluated for selected samples by head space solid-phase microextraction followed by a gas chromatography-mass spectrometry (HS-SPME-GC-MS) analysis. The used SPME-GC-MS method and its 
performance control is described in detail in LEHTONEN ET AL. (LEHTONEN ET AL., 2016). Triplicate measurements were done using $0.5 \mathrm{~g}$ of the dry, fish oil loaded aerogel particles per measurement. The fish oil and fish oil loaded samples were sent in dry atmosphere from Hamburg to Helsinki within 3-4 days. They were analyzed approx. one week after arrival and stored in the fridge $(+4 \mathrm{C})$ prior to analysis. The results are reported as average peak areas over three replicate samples.

\subsubsection{Storage at defined relative humidity}

222

223

224

225

226

227

228

Storage experiments were conducted at a relative humidity $(\mathrm{rH})$ of $11 \%$ and $33 \%$ and at room temperature $\left(20^{\circ} \mathrm{C}\right)$, representing dry storage conditions. WPI, EWP and NaCas aerogel particles without loading and fish oil loaded WPI and EWP particles were stored over 2, 4, 8 and 12 weeks. The respective $\mathrm{rH}$ was created with saturated salt solutions of $\mathrm{LiCl}(\mathrm{rH}$ $11 \%$ ) and $\mathrm{MgCl}_{2}(\mathrm{rH} 33 \%)$ (Greenspan, 1977). Small, flat bottomed dishes were filled with a layer of about $2 \mathrm{~g}$ of particles and placed on a rack just above the surface of the salt solution in sealable containers. An absorption or desorption of water was determined gravimetrically.

\section{Results and discussion}

\subsection{Loading of aerogel particles by adsorption of fish oil from supercritical $\mathrm{CO}_{2}$}

First, the kinetics of the static fish oil adsorption from supercritical $\mathrm{CO}_{2}$ were measured at the highest pressure $(18 \mathrm{MPa})$ and lowest investigated temperature $\left(40^{\circ} \mathrm{C}\right)$ to determine the longest equilibration time in the utilized high-pressure equipment since adsorption is generally favored at these conditions. When investigating other system conditions, it was assumed that the equilibrium was reached in any case when the time was longer than the equilibration time at $18 \mathrm{MPa}$ and $40^{\circ} \mathrm{C}$. The adsorpt ion kinetic results for the investigated carrier materials are presented in form of the fish oil loading (loaded fish oil mass per mass of unloaded/pure aerogel micro-particles) in Figure 3.

The highest fish oil loadings (up to $0.74 \mathrm{~g}$ fish oil/g aerogel) were achieved for EWP-aerogels and WPI I-aerogels. The corresponding thermodynamic equilibria were reached after $48 \mathrm{~h}$. Lower fish oil loadings per gram aerogel and shorter equilibration times ( $16 \mathrm{~h}$ and $20 \mathrm{~h}$ ) were observed for the NaCas-aerogels and the WPI II-aerogels.

In principal three loading mechanisms of the porous aerogel structure are conceivable: adsorption, capillary condensation (including adsorption) or absorption (entrapment of fish oil molecules in solid protein matrix). In case of loading the protein aerogels with fish oil, it is not possible to exclude any mechanism or a combination of mechanisms. In our opinion, the adsorption of fish oil molecules onto the high inner surface area of the aerogel in combination 
with a partially capillary condensation seems most reasonable. In case of complete capillary condensation, we would have expected higher fish oil loadings: using a fish oil density of $925 \mathrm{~kg}$ fish oil $/ \mathrm{m}^{3}$ and the pore volume of WPI I-aerogel particles $\left(0.00155 \mathrm{~m}^{3} / \mathrm{kg}\right.$ aerogel) would lead for example to a loading of $1.43 \mathrm{~g}$ fish oil $/ \mathrm{g}$ aerogel. The absorption of fish oil in the solid protein aerogel backbone seem rather improbable. Although we cannot exclude any of the loading mechanism, we used the word "adsorption" in this publication as synonym for the most probable aerogel loading mechanism (adsorption combined with partially capillary condensation).

In a second step, the influence of pressure and temperature was investigated. The temperature range was limited to $31^{\circ} \mathrm{C}$ (critical te mperature of $\mathrm{CO}_{2}$ ) and $60{ }^{\circ} \mathrm{C}$ (lowest denaturing temperature of the utilized proteins). Within this range only a slight influence of the temperature on the equilibrium fish oil loading could be observed (increasing temperature led to decreasing loading; data not shown). The pressure influence on the equilibrium fish oil loadings for different aerogel matrices is shown in Figure 4. As expected, the equilibrium fish oil loading increases for all carrier matrices with increasing system pressure similar to the findings of COMIN ET AL., who investigated the static supercritical $\mathrm{CO}_{2}$ impregnation of barley $\beta$-glucan aerogels with flax oil (Comin et al., 2012). A higher system pressure shifts the equilibrium of the fish oil being solubilized in the supercritical $\mathrm{CO}_{2}$ bulk phase or being adsorbed on the aerogel surface towards the adsorbed fish oil on the aerogel surface. Additionally, the solubility of fish oil in supercritical $\mathrm{CO}_{2}$ increases with increasing system pressure (Gupta and Shim, 2006) allowing higher loadings on the aerogel surface. COMIN ET AL. determined an oil loading of approx. $0.887 \mathrm{~g}$ flax oil $/ \mathrm{g}$ aerogel at $15 \mathrm{MPa}$ and $40 \mathrm{C}$ for the static impregnation process (Comin et al., 2012) which is higher than the fish oil loadings measured in this study (Figure 4). One explanation could be that COMIN ET AL. used fast depressurization rates in their study, resulting into oil precipitation and thus high aerogel loadings. The precipitation phenomenon is well known when the pressure is released relatively fast for compounds which are soluble in dense $\mathrm{CO}_{2}$ (Gurikov and Smirnova, 2018). Another reason could be that the aerogel structure of barley $\beta$-glucan aerogels favors the oil loading more than the protein aerogel structures. Since the barley $\beta$-glucan aerogel structure was not characterized in detail (Comin et al., 2012) no structure comparison is possible here.

279 We tried to avoid oil precipitation using slow depressurization rates (- $\mathrm{dp} / \mathrm{dt}<0.1 \mathrm{MPa} / \mathrm{min}$ ) to avoid agglomerated particles due to precipitated (fish) oil onto the particles outer surface to retain the free-flowing properties of the aerogel particles. Faster depressurization rates were tried which resulted in higher fish oil loadings, precipitated fish oil onto the particles outer surface and agglomerated particles. The particles seemed "wet" and did not retain their freeflowing properties. 
Since the adsorption is dependent on the accessible inner surface of the aerogel particles, the loaded fish oil mass was related to the respective BET-surface area (Figure 5). Additionally, the pressure related fish oil solubility in supercritical $\mathrm{CO}_{2}$ (Gupta and Shim, 2006) was used instead of the system pressure to construct isotherms using the Freundlich and Langmuir approach (Foo and Hameed, 2010) (Figure 5). This isotherm construction differs from the studies of PANTIC ET AL. and MARCO AND REVERCHON, where a constant pressure and concentrations below the saturation concentration in supercritical $\mathrm{CO}_{2}$ were used to apply Langmuir and Freundlich models for the impregnation of alginate and starch aerogels with vitamins (Marco and Reverchon, 2017; Pantić et al., 2016a). Thus, a meaningful comparison to their findings does not seem reasonable. As expected, the specific loadings increase with increasing fish oil solubility in $\mathrm{CO}_{2}$ (Figure 5). Additionally, different WPI-aerogels (WPII and II) having different BET-surface areas show similar loadings per BET-surface area. Therefore, it can be concluded that an increase of the BET-surface area leads generally to higher loadings per gram aerogel. The specific loadings on the EWP- and NaCas-aerogels were described more precisely by the Freundlich model than by the Langmuir model whereas the specific loading on the WPI-aerogels could not be described adequately by both investigated models.

A possible, simple alternative to the adsorption from supercritical $\mathrm{CO}_{2}$ is to load the aerogel particles by direct mixing with fish oil (details are given in the Supplementary information). This method led to significantly higher loadings, but large parts of the fish oil stick to the outside of the particles as liquid bridges between the aerogel particles instead of being sorbed by the porous matrices (Figure 6). Thus, the flowability of the powder is significantly decreased and no protection of the fish oil from oxidation can be expected. In comparison, the supercritical $\mathrm{CO}_{2}$ loading method avoids liquid bridges, since the fish oil is rather adsorbed on the inner and outer surface of the aerogel matrices and the particles stay dry and free-flowing (as proven for all three loaded protein sources, Figure 6). We believe, these phenomena are advantageous in later industrial applications, where the powder flowability plays a role.

313 AHMADI ET AL. presented another fish oil loading method (Ahmadi et al., 2016): Whey protein 314 gel monoliths were freeze dried to cryogels (BET-surface areas $<5 \mathrm{~m}^{2} / \mathrm{g}$ ) and soaked in a 315 hexane-fish oil-solution whereby the hexane was evaporated subsequently. The achieved specific loading of AHMADI ET AL. ( $0.013 \mathrm{~g}$ fish oil $/ \mathrm{m}^{2}$ cryogel) is seven times higher than the fish oil adsorption from supercritical $\mathrm{CO}_{2}$ at $40{ }^{\circ} \mathrm{C}$ and $18 \mathrm{MPa}$ onto WPI-aerogel particles,

318 but the absolute loading ( $0.026 \mathrm{~g}$ fish oil/g cryogel) is more than one order smaller (Ahmadi 319 et al., 2016). 
Overall, loadings up to $0.74 \mathrm{~g}$ fish oil $/ \mathrm{g}$ aerogel could be achieved onto the protein aerogels using static supercritical $\mathrm{CO}_{2}$ impregnation. Slightly higher loadings $(0.916 \mathrm{~g}$ oil $/ \mathrm{g}$ aerogel) were reached for the loading of flax oil onto barley $\beta$-glucan aerogels (Comin et al., 2012) showing that protein aerogels exhibit a similar potential as carrier material for oils compared to polysaccharide aerogels. Compared to the vitamin loadings of polysaccharide-based aerogels the fish oil loadings on protein aerogels show more than three times higher values (Haimer et al., 2010; Marco and Reverchon, 2017; Pantić et al., 2016b; Pantić et al., 2016a). Additionally, the achieved fish oil loading is higher than the usual loading of 0.333 to $0.5 \mathrm{~g}$ fish oil/g wall material reported for the microencapsulation of fish oil by spray drying (Encina et al., 2016). For a later industrial application, the diffusion driven static adsorption from supercritical $\mathrm{CO}_{2}$ should definitely be replaced by a dynamic adsorption to shorten the process time. A circulation pump could accelerate the mass transfer of valuable compounds in the fluid phase by convection.

\subsection{Fat composition of loaded fish oil}

Since fish oil is a mixture of different tri-, di-, monoglycerides and free fatty acids the question arises, whether the dissolution in supercritical $\mathrm{CO}_{2}$ or the adsorption are selective or nonselective. Therefore, the compositions of the fresh fish oil, the fish oil from the aerogel particles and from the autoclave were analyzed. Figure 7 shows that tri-glycerides were adsorbed in a higher proportion and free fatty acids in a lower proportion compared to the composition of the fresh fish oil. Additionally, the cholesterol proportion is slightly higher for all three loaded aerogel matrices compared to the fresh fish oil and corresponding fish oil residues in the autoclave. Further analyses of the fish oil compositions were conducted for all three protein matrices at different adsorption pressures and adsorption times, but no clear trends could be observed hereby. This is positive for the process development, because it is possible to choose the process conditions without effects on the fish oil composition.

The fatty acid composition of the utilized fish oil and fish oil loaded WPI- and EWP-aerogel particles was analyzed, whereas the absolute mass of fish oil being adsorbed on the surface of the NaCas-aerogel particles was too low for analysis. Figure 8 shows that the utilized fish oil exhibits a similar fatty acid profile as the adsorbed fish oil on the aerogel particles' surfaces and the fish oil residues in the autoclave (non-adsorbed fish oil). Thus, the fatty acid distribution changes only slightly during the adsorption process of fish oil from supercritical $\mathrm{CO}_{2}$. A slightly smaller proportion of the essential $\omega$-3-fatty acids (C20:5 and C22:6) was determined in case of the loaded EWP-aerogels. One reason for this could be that a small portion of the sensitive $\omega$-3-fatty acids was oxidized after the adsorption onto the EWPsurface and thus was decomposed into volatile oxidation products (Section 3.3). For the 
similar to the high content of C20:5 and C22:6 in micro encapsulated tuna oil (spray dried tuna oil-in-water-emulsions) (Shen et al., 2010). Thus, the requirement to load high portions of $\omega$-3-fatty acids is fulfilled for the supercritical $\mathrm{CO}_{2}$ impregnation of aerogels as new loading technique for fish oil.

\subsection{Volatile compounds of loaded fish oil}

361

362

363

364

365

366

367

368

369

370

371

372

373

374

375

376

377

378

379

380

381

382

383

384

385

386

387

388

389

390

To investigate the odor and the oxidative status of the fish oil loaded aerogel particles the volatile compounds were examined by static head-space GC-FID. Propanal, pentanal and 1penten-3-ol were identified in the head spaces of the utilized fish oil and fish oil loaded aerogels. These compounds as well as 2-pentenal being similar to pentanal are well-known as volatile oxidation products of $\omega$-3-fatty acids of fish oil (Miyashita et al., 2018). The highest volatiles per gram fish oil were measured for the fish oil (Figure 9), indicating that the odor of the pure fish oil is higher than for the fish oil being adsorbed on the surface of the aerogel matrices. A reason for that could be that the fish oil is stabilized by the adsorption and thus less oxidized when heated up to $100^{\circ} \mathrm{C}$ for one hour (during head-space GC analysis). Another reason could be that the smaller volatile molecules were flushed out during the depressurization of the supercritical $\mathrm{CO}_{2}$ or were adsorbed in a lower proportion than the larger non-volatile molecules (cf. Figure 7). Comparing the loaded aerogels, the WPI-aerogel particles showed the lowest and NaCas-aerogel particles the highest quantity of volatiles per gram loaded fish oil (Figure 9).

To analyze the fish oil volatiles at lower temperature, HS-SPME-GC-MS measurements were conducted. High temperatures favor the oxidation of the $\omega-3$ fatty acids and lead to degradation of the oxidation products (Miyashita et al., 2018). The used SPME procedure releases and extracts the volatiles at low temperature $\left(40^{\circ} \mathrm{C}\right.$ ) within $40 \mathrm{~min}$ (Lehtonen et al., 2016), but it is selective since low boiling compounds may be discriminated during the injection into the GC and thus favors the extraction of higher boiling compounds (up to 250 C) (Lehtonen et al., 2016; Miyashita et al., 2018). Therefore, the previously determined volatiles (propanal, pentanal and 1-penten-3-ol) could not or only to a small extent be detected (details are given in the supplementary information). Overall, remarkable high amounts of ethanol (and its denaturant 2-butanone (MEK) (Kleemann et al., 2018)) could be observed for all unloaded aerogel particles. The drying of the aerogel particles seems not to remove the denatured ethanol completely. It might stay adsorbed on the high specific surface area of the aerogels. Nevertheless, the aerogel properties lay in the expected range and longer dryings did not change the properties significantly. In later industrial applications ethanol without any denaturant can be used, so that the MEK as denaturing substance is of minor importance for industrial food applications. 
To get an impression of the volatiles contained in the fish oil, the unloaded and fish oil loaded protein aerogel particles, the summarized identified volatiles (without ethanol), the volatiles classified as oxidative markers (Gómez-Cortés et al., 2015; Miyashita et al., 2018) and the volatile ethanol in the respective samples (detailed results in supplementary information) are shown in Figure 10 and Figure 11.

396

As expected, the pure, cooled fish oil showed the lowest amounts of oxidative markers and ethanol while the oxidative status of the (non-adsorbed) fish oil remaining in the autoclave increases during the adsorption process (Figure 10) probably due to the raised temperature in the autoclave ( $40^{\circ} \mathrm{C}$ compared to $3^{\circ} \mathrm{C}$ in the fri dge). The total volatile content of the fish oil is in the same range as for unloaded WPI- and NaCas-aerogel particles (Figure 10). The high content of oxidative markers in case of all unloaded aerogel particles could be explained by a high contact area between protein gel particles and sun flower oil during the water (protein solution) in oil emulsion gelation step within production (Kleemann et al., 2018). Although the gel particles were separated from most of the oil after the gelation it seems that the oil residues stick to the particles' outer surfaces, get in contact with oxygen after drying and thus smell.

The ethanol smell of the aerogels is reduced during the adsorption process of fish oil from supercritical $\mathrm{CO}_{2}$ (Figure 10) since ethanol is miscible with $\mathrm{scCO}_{2}$ at the utilized adsorption conditions. Thus, the ethanol content between the different aerogel particles (being processed in the same autoclave) and the remaining fish oil at the bottom of the autoclave is equilibrated. This effect seems to be independent of the aerogel's pore structure and loaded fish oil mass (Figure 11). For the total amount of volatiles (without ethanol) no clear trend is observable (Figure 10): It increases for WPI- and NaCas-aerogel particles and decreases for EWP-aerogel particles during the adsorption process. However, the total amount of oxidative markers decreases for all investigated aerogel particles during the loading (Figure 10). It seems that the supercritical $\mathrm{CO}_{2}$ extracts large portions of the initial volatiles ( $\hat{=}$ volatiles of unloaded aerogels) from the aerogels since a higher pressure (18 MPa) and thus a higher $\mathrm{CO}_{2}$ density and solvating power is used during the fish oil impregnation process compared to the supercritical drying process (12 MPa), which is used beforehand to produce the aerogels. Additionally, the initial volatiles in the porous aerogel structure could be flushed out during pressurization and depressurization of the impregnation process.

Due to varying fish oil loadings the volatiles were related to the containing fish oil mass and compared with the fish oil before and after the adsorption process (Figure 11): WPI- and EWP-aerogels show a similar oxidative status like the autoclaved fish oil, whereas $\mathrm{NaCas}-$ aerogels exhibit the highest content of total volatiles, oxidative markers and ethanol. One reason for this could be a difference in hydrophobicity of the aerogels' inner surfaces. In case 
of higher hydrophobicity, stronger interactions with the fish oil molecules and thus a lower content of volatiles and oxidation are expected. During heat induced gelation, hydrophobic sites of the WPI- and EWP-proteins become exposed to the protein surface and interact intra- or intermolecularly, whereas enzymatic crosslinking of NaCas does not increase the hydrophobicity of the proteins surface (Kleemann et al., 2018). For this reason and their low loading capacity (Section 3.1) it is recommended to use WPI- or EWP-aerogel particles as carrier material instead of NaCas-aerogel particles.

In summary, WPI- and EWP-aerogels are possible carrier materials for fish oil regarding loading capacity and oxidative status of the loaded fish oil. Nevertheless, the oxidative status of the fish oil loaded on the particles is higher than the untreated fish oil stored at $3^{\circ} \mathrm{C}$. A loading of the fish oil onto aerogel particles may reduce oxidation in applications, where the fish oil containing food is heated up (cooked, roasted, grilled or baked). To prevent fish oil oxidation the loaded aerogel particles could be coated subsequently (Goslinska et al., 2019) to encapsulate the fish oil within the aerogel particles as shown by AHMADI ET AL. for WPIcryogels (Ahmadi et al., 2016).

\subsection{Storage behavior of fish oil loaded protein aerogel particles}

The shelf life of the unloaded protein aerogel particles is relevant, when the particles are produced in advance and the loading is conducted elsewhere. The storage of unloaded WPI, EWP- and NaCas-aerogel particles was conducted at a relative humidity $(\mathrm{rH})$ of $11 \%$ and $33 \%$ for 12 weeks. The weight gain due to water uptake was less than $1 \%$ and no distinct optical changes were observed for all three protein systems during storage time. WPI and NaCas particles in particular kept their very good free flowing properties, remained unchanged and only little dust was observed. EWP particles showed a slightly cemented layer on the top of long stored samples. However, these clumps easily dissociated when agitated. EWP particles generated a lot more dust because of their small particle size.

Storage experiments of fish oil loaded aerogel particles reveal the protective properties of the aerogel particles and possible changings during storage. WPI- and EWP-aerogel particles, which were loaded with fish oil from supercritical $\mathrm{CO}_{2}$, showed similar storage behavior as the unloaded particles. The relative weight change was for all tested samples about $1 \%$ (see supplementary information). No fish oil leaked from the particles during the entire storage time and the loaded particles kept their free-flowing properties.

The variation of volatile compounds of the fish oil loaded WPI- and EWP-aerogel particles was determined by means of SHS-GC-FID analysis. A slight increase of the sum of identified volatiles (without ethanol) can be observed for both aerogel systems during storage (Figure 12), whereby the higher relative humidity and the adsorption on EWP-aerogel particles 
462

463

464

465

466

467

468

469

470

471

472

473

474

475

476

477

478

479

480

481

482

483

484

485

486

487

488

489

490

491

492

493

494

enhances the quantity of volatiles. The sum of volatiles of the fish oil utilized for the loading is two orders of magnitude higher (cf. Figure 9) than for the fish oil loaded aerogel particles being stored (Figure 12). Since the samples were heated up during the analysis it can be concluded that the stabilizing effect of the adsorption for the fish oil at raised temperatures maintains over the storage time of 12 weeks.

Overall, the fish oil is bound to the network structure of the protein aerogel particles and the microcapsules represent a stable product over a storage time of 12 weeks.

\section{Conclusions and outlook}

The potential of protein aerogels as carrier material for food additives was investigated. Protein aerogel micro-particles were successfully loaded with fish oil by static supercritical $\mathrm{CO}_{2}$ impregnation. Loadings up to $0.74 \mathrm{~g}$ fish oil $/ \mathrm{g}$ aerogel could be achieved for WPI- and EWP-aerogels while the aerogel micro-particles retained their free-flowing properties and the fish oil retained its composition. Additionally, the loaded fish oil showed less volatile oxidation products of $\omega-3$ fatty acids compared to free/unbound fish oil at high temperature. Fish oil loaded WPI-aerogels exhibited slightly higher proportions $\omega-3$ fatty acids and slightly lower volatile oxidation products of $\omega-3$ fatty acids compared to fish oil loaded EWP-aerogels. NaCas-aerogels showed the lowest fish oil loading and the highest ratio of volatiles related to the loaded fish oil mass. During a storage time of 12 weeks the fish oil loaded aerogel particles kept their free-flowing properties representing a stable product without any fish oil leaking.

Overall the protein aerogel micro-particles are suitable as carrier material for sensitive oils. To reduce the oxidation of the loaded (fish) oil further a second compound could be coimpregnated as antioxidant (for example tocopherols (Miyashita et al., 2018)) or an additional coating could be applied in future studies. Additionally, a dynamic process instead of a static supercritical $\mathrm{CO}_{2}$ impregnation process should be investigated to decrease the process time.

\section{Acknowledgements}

This IGF Project AiF $17485 \mathrm{~N}$ of the FEl was supported via AiF within the program for promoting the Industrial Collective Research (IGF) of the German Ministry of Economic Affairs and Energy (BMWi), based on a resolution of the German Parliament. Ilka Selmer was supported by a scholarship of Pro Exzellenzia. Mari Lehtonen was supported by Jane and Aatos Erkko Foundation (WOODLIPS project), and Kirsi S. Mikkonen was supported by the Academy of Finland (project number 268144). We would like to thank Jan Philipp Köther, Florian Lorenzen, Judith Niebuhr, Jonathan von der Heide and the Central Laboratory of 
Analytical Chemistry of the Hamburg University of Technology for their experimental

measurements.

497

498

499

500

501

502

503

504

505

506

507

508

509

510

511

512

513

514

515

516

517

518

519

520

521

522

523

524

525

526

527

\section{Notes}

Declarations of interest: none

\section{References}

Ahmadi, M., Madadlou, A., Saboury, A.A., 2016. Whey protein aerogel as blended with cellulose crystalline particles or loaded with fish oil. Food Chemistry 196, 1016-1022.

Alnaief, M., Alzaitoun, M.A., García-González, C.A., Smirnova, I., 2011. Preparation of biodegradable nanoporous microspherical aerogel based on alginate. Carbohydrate Polymers 84 (3), 1011-1018.

Alnaief, M., Antonyuk, S., Hentzschel, C.M., Leopold, C.S., Heinrich, S., Smirnova, I., 2012. A novel process for coating of silica aerogel microspheres for controlled drug release applications. Microporous and Mesoporous Materials 160, 167-173.

Alnaief, M., Smirnova, I., Antonyuk, S., Heinrich, S., Roth, S., 2010. A Novel Process for Production of Aerogel Microspheres and their Coating with Polymeric Materials in a Spouted Bed. Chemie Ingenieur Technik 82 (9), 1466-1467.

Bakry, A.M., Abbas, S., Ali, B., Majeed, H., Abouelwafa, M.Y., Mousa, A., Liang, L., 2016. Microencapsulation of Oils: A Comprehensive Review of Benefits, Techniques, and Applications. Comprehensive Reviews in Food Science and Food Safety 15 (1), 143-182.

Baldino, L., Cardea, S., Reverchon, E., 2016. Loaded Silk Fibroin Aerogel Pr oduction by Supercritical Gel Drying Process for Nanomedicine Applications. Chemical engineering transactions 49, 343-348.

Betz, M., García-González, C.A., Subrahmanyam, R.P., Smirnova, I., Kulozik, U., 2012. Preparation of novel whey protein-based aerogels as drug carriers for life science applications. The Journal of Supercritical Fluids 72, 111-119.

Cicco, F. de, Russo, P., Reverchon, E., García-González, C.A., Aquino, R.P., Del Gaudio, P., 2016. Prilling and supercritical drying: A successful duo to produce core-shell polysaccharide aerogel beads for wound healing. Carbohydrate Polymers 147, 482-489.

Comin, L.M., Temelli, F., Saldaña, M.D.A., 2012. Barley $\beta$-glucan aerogels as a carrier for flax oil via supercritical CO2. Journal of Food Engineering 111 (4), 625-631.

DIN-Normenausschuss Lebensmittel und landwirtschaftliche Produkte, 2017. Tierische und pflanzliche Fette und Öle - Gaschromatographie von Fettsäuremethylestern - Teil 2: Herstellung von Fettsäuremethylestern. 
Encina, C., Vergara, C., Giménez, B., Oyarzún-Ampuero, F., Robert, P., 2016. Conventional spray-drying and future trends for the microencapsulation of fish oil. Trends in Food Science \& Technology 56, 46-60.

Foo, K.Y., Hameed, B.H., 2010. Insights into the modeling of adsorption isotherm systems. Chemical Engineering Journal 156 (1), 2-10.

García-González, C.A., Alnaief, M., Smirnova, I., 2011. Polysaccharide-based aerogelsPromising biodegradable carriers for drug delivery systems. Carbohydrate Polymers 86 (4), 1425-1438.

García-González, C.A., Jin, M., Gerth, J., Alvarez-Lorenzo, C., Smirnova, I., 2015. Polysaccharide-based aerogel microspheres for oral drug delivery. Carbohydrate Polymers 117, 797-806.

Gómez-Cortés, P., Sacks, G.L., Brenna, J.T., 2015. Quantitative analysis of volatiles in edible oils following accelerated oxidation using broad spectrum isotope standards. Food Chemistry 174, 310-318.

Gonçalves, V.S.S., Gurikov, P., Poejo, J., Matias, A.A., Heinrich, S., Duarte, C.M.M., Smirnova, I., 2016. Alginate-based hybrid aerogel microparticles for mucosal drug delivery. European journal of pharmaceutics and biopharmaceutics : official journal of Arbeitsgemeinschaft fur Pharmazeutische Verfahrenstechnik e.V 107, 160-170.

Goslinska, M., Selmer, I., Kleemann, C., Kulozik, U., Smirnova, I., Heinrich, S., 2019. Novel technique for measurement of coating layer thickness of fine and porous particles using focused ion beam. Particuology 42, 190-198.

Greenspan, L., 1977. Humidity fixed points of binary saturated aqueous solutions. Journal of Research of the National Bureau of Standards Section A: Physics and Chemistry 81A (1), 89.

Gupta, R.B., Shim, J.-J., 2006. Solubility in supercritical carbon dioxide. CRC Press, Boca Raton, Fl.

Gurikov, P., Smirnova, I., 2018. Amorphization of drugs by adsorptive precipitation from supercritical solutions: A review. The Journal of Supercritical Fluids 132, 105-125.

Haimer, E., Wendland, M., Schlufter, K., Frankenfeld, K., Miethe, P., Potthast, A., Rosenau, T., Liebner, F., 2010. Loading of Bacterial Cellulose Aerogels with Bioactive Compounds by Antisolvent Precipitation with Supercritical Carbon Dioxide. Macromolecular Symposia 294 (2), 64-74.

Kleemann, C., Selmer, I., Smirnova, I., Kulozik, U., 2018. Tailor made protein based aerogel particles from egg white protein, whey protein isolate and sodium caseinate: Influence of the preceding hydrogel characteristics. Food Hydrocolloids 83, 365-374. 
Lee, H., Kizito, S.A., Weese, S.J., Craig-Schmidt, M.C., Lee, Y., Wei, C.-I., An, H., 2003. Analysis of Headspace Volatile and Oxidized Volatile Compounds in DHA-enriched Fish Oil on Accelerated Oxidative Storage. Journal of Food Science 68 (7), 2169-2177.

Lehtonen, M., Teräslahti, S., Xu, C., Yadav, M.P., Lampi, A.-M., Mikkonen, K.S., 2016. Spruce galactoglucomannans inhibit lipid oxidation in rapeseed oil-in-water emulsions. Food Hydrocolloids 58, 255-266.

Lovskaya, D.D., Lebedev, A.E., Menshutina, N.V., 2015. Aerogels as drug delivery systems: In vitro and in vivo evaluations. The Journal of Supercritical Fluids.

Maleki, H., Durães, L., García-González, C.A., Del Gaudio, P., Portugal, A., Mahmoudi, M., 2016. Synthesis and biomedical applications of aerogels: Possibilities and challenges. Advances in colloid and interface science 236, 1-27.

Marco, I. de, Reverchon, E., 2017. Starch aerogel loaded with poorly water-soluble vitamins through supercritical CO 2 adsorption. Chemical Engineering Research and Design 119, 221-230.

Marin, M.A., Mallepally, R.R., McHugh, M.A., 2014. Silk fibroin aerogels for drug delivery applications. The Journal of Supercritical Fluids 91 (0), 84-89.

Mehling, T., Smirnova, I., Guenther, U., Neubert, R.H.H., 2009. Polysaccharide-based aerogels as drug carriers. Journal of Non-Crystalline Solids 355 (50-51), 2472-2479.

Mikkonen, K.S., Parikka, K., Ghafar, A., Tenkanen, M., 2013. Prospects of polysaccharide aerogels as modern advanced food materials. Trends in Food Science \& Technology 34 (2), 124-136.

Miyashita, K., Uemura, M., Hosokawa, M., 2018. Effective Prevention of Oxidative Deterioration of Fish Oil: Focus on Flavor Deterioration. Annual Review of Food Science and Technology 9, 209-226.

Mustapa, A.N., Martín, Á., Cocero, M.J., 2018. Alginate aerogels dried by supercritical CO2 as herbal delivery carrier. Malaysian Journal of Analytical Science 22 (3).

Obaidat, R.M., Alnaief, M., Mashaqbeh, H., 2018. Investigation of Carrageenan Aerogel Microparticles as a Potential Drug Carrier. AAPS PharmSciTech 19 (5), 2226-2236.

Pantić, M., Knez, Ž., Novak, Z., 2016a. Supercritical impregnation as a feasible technique for entrapment of fat-soluble vitamins into alginate aerogels. Journal of Non-Crystalline Solids 432, 519-526.

Pantić, M., Kotnik, P., Knez, Ž., Novak, Z., 2016b. High pressure impregnation of vitamin D 3 into polysaccharide aerogels using moderate and low temperatures. The Journal of Supercritical Fluids 118, 171-177.

Salgado, M., Santos, F., Rodríguez-Rojo, S., Reis, R.L., Duarte, Ana Rita C., Cocero, M.J., 2017. Development of barley and yeast $\beta$-glucan aerogels for drug delivery by supercritical fluids. Journal of CO2 Utilization 22, 262-269. 
600

601

602

603

604

605

606

607

608

609

610

611

612

613

614

615

616

617

618

619

620

621

622

Selmer, I., Kleemann, C., Kulozik, U., Heinrich, S., Smirnova, I., 2015. Development of egg white protein aerogels as new matrix material for microencapsulation in food. The Journal of Supercritical Fluids 106, 42-49.

Shen, Z., Augustin, M.A., Sanguansri, L., Cheng, L.J., 2010. Oxidative stability of microencapsulated fish oil powders stabilized by blends of chitosan, modified starch, and glucose. Journal of Agricultural and Food Chemistry 58 (7), 4487-4493.

Simon, A., Stahl, A., 2016. Fettsäuremethylester (FAME) mittels GC-FID.M03.004.01, Hamburg, Hamburg University of Technology, Central Laboratory of Analytical Chemistry.

Stergar, J., Maver, U., 2016. Review of aerogel-based materials in biomedical applications. Journal of Sol-Gel Science and Technology 77 (3), 738-752.

Tavares, G.M., Croguennec, T., Carvalho, A.F., Bouhallab, S., 2014. Milk proteins as encapsulation devices and delivery vehicles: Applications and trends. Trends in Food Science \& Technology 37 (1), 5-20.

Ulker, Z., Erkey, C., 2014. An emerging platform for drug delivery: Aerogel based systems. Journal of controlled release : official journal of the Controlled Release Society 177, 5163.

Veres, P., Sebők, D., Dékány, I., Gurikov, P., Smirnova, I., Fábián, I., Kalmár, J., 2018. A redox strategy to tailor the release properties of $\mathrm{Fe}(\mathrm{III})$-alginate aerogels for oral drug delivery. Carbohydrate Polymers 188, 159-167.

Zhao, S., Malfait, W.J., Guerrero-Alburquerque, N., Koebel, M.M., Nyström, G., 2018. Biopolymer Aerogels and Foams: Chemistry, Properties, and Applications. Angewandte Chemie (International ed. in English) 57 (26), 7580-7608. 

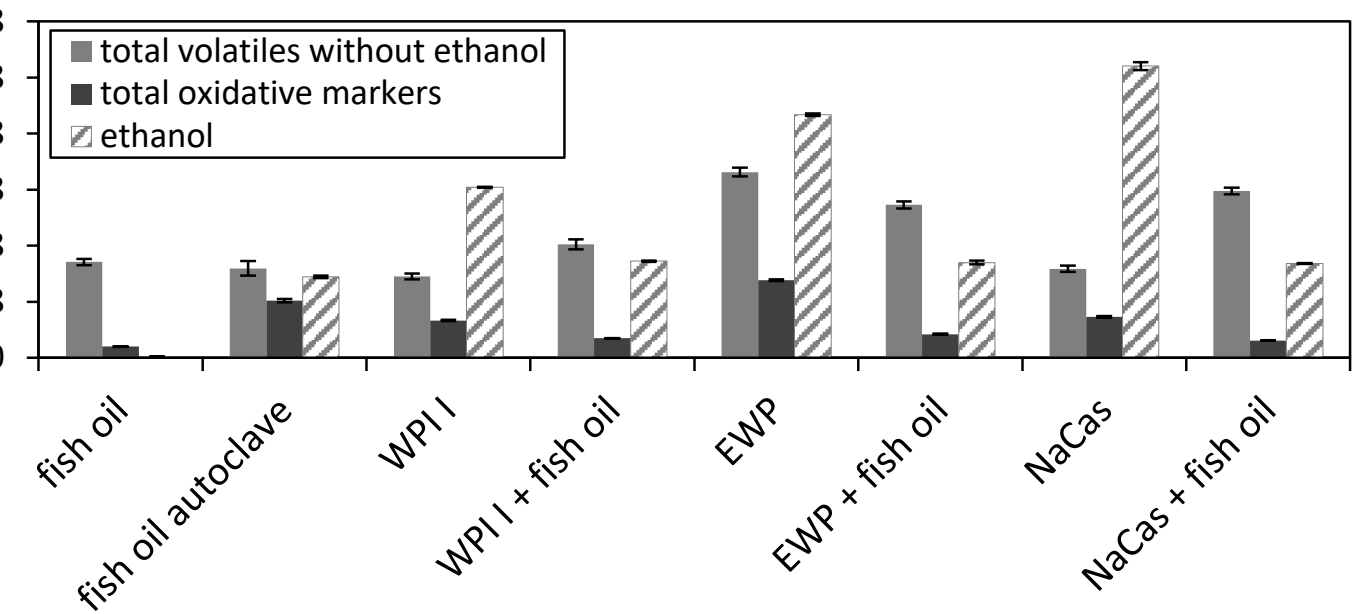

Figure 10: Total volatiles without ethanol, total volatiles classified as oxidative markers for TGAs and the volatile ethanol for the utilized fish oil (stored at $3^{\circ} \mathrm{C}$ ), the non-adsorbed remaining fish oil in the autoclave, the unloaded aerogel particles and fish oil loaded aerogel particles. The volatiles were related to $0.5 \mathrm{~g}$ sample weight. Fish oil adsorption conditions: $\mathrm{P}=18 \mathrm{MPa}, \mathrm{T}=313 \mathrm{~K}$. 


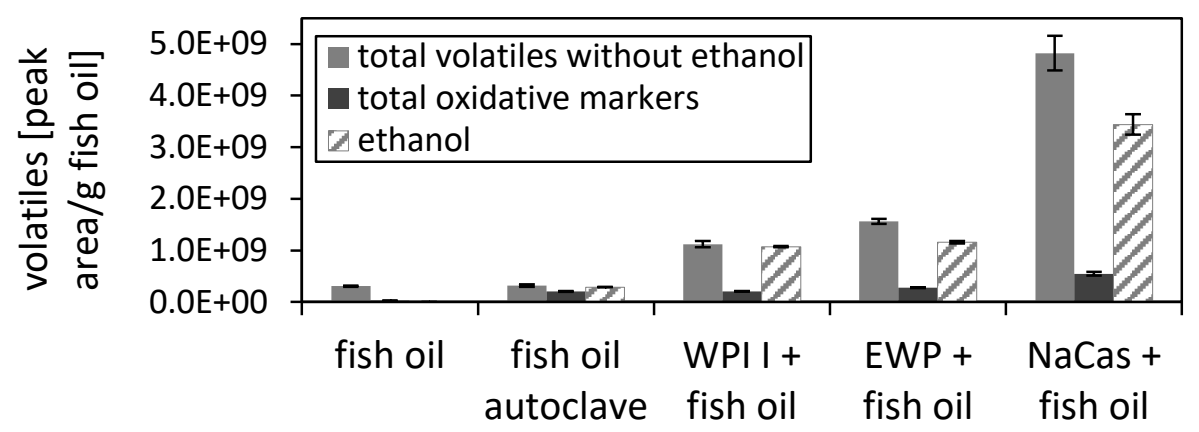

Figure 11: Total volatiles without ethanol, total volatiles classified as oxidative markers for TGAs and the volatile ethanol for the fish oil, the remaining fish oil in the autoclave and fish oil loaded aerogel particles. The volatiles were related to $1 \mathrm{~g}$ fish oil. Fish oil adsorption conditions: $P=18 \mathrm{MPa}$, $\mathrm{T}=313 \mathrm{~K}$. 


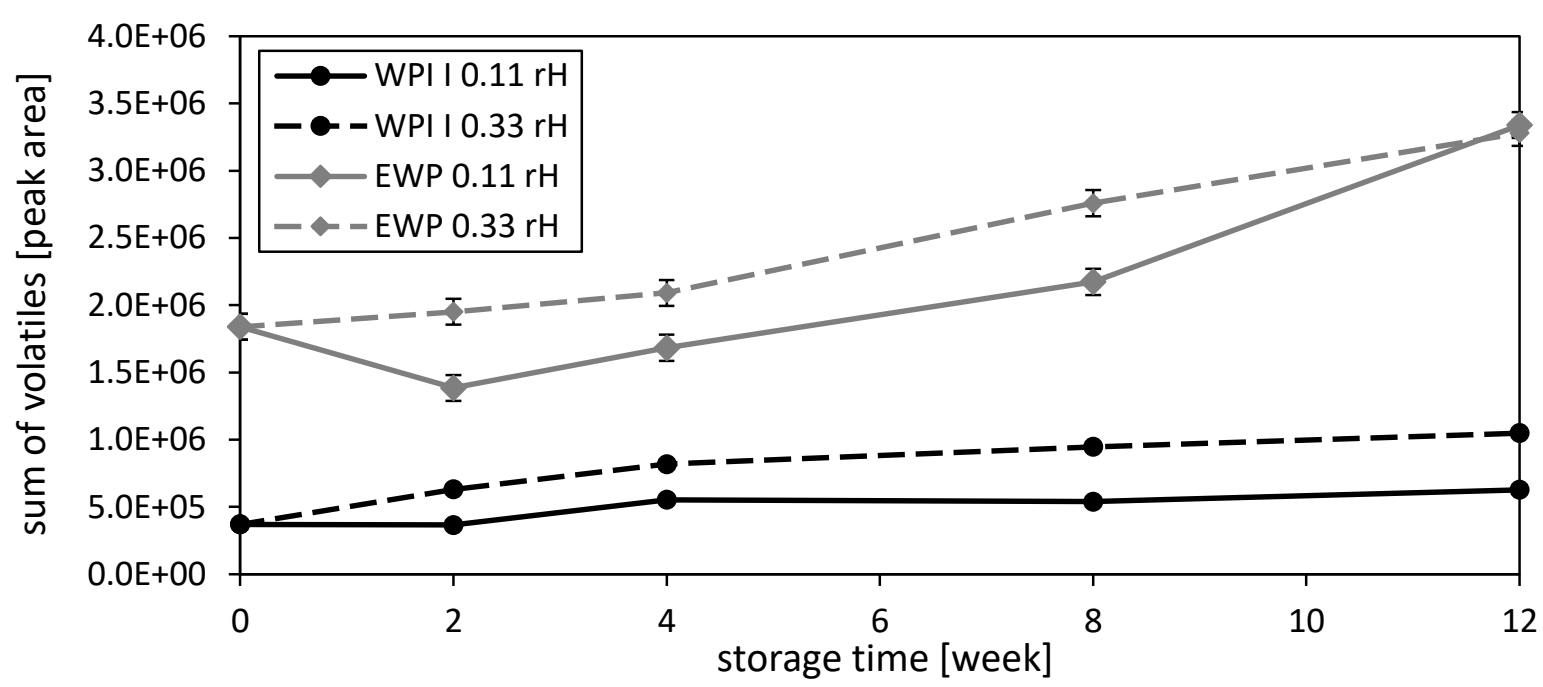

Figure 12: Sum of the volatiles propanal, pentanal and 1-penten-3-ol of fish oil loaded WPI I- and EWP-aerogel particles as function of the storage time. The volatiles are related to $1 \mathrm{~g}$ fish oil. Fish oil adsorption conditions: $P=18 \mathrm{MPa}, T=313 \mathrm{~K}$. Storage conditions: $\mathrm{T}=298 \mathrm{~K}$, humidity=0.11 $\mathrm{rH}$ (solid lines) and $0.33 \mathrm{rH}$ (dashed lines). 


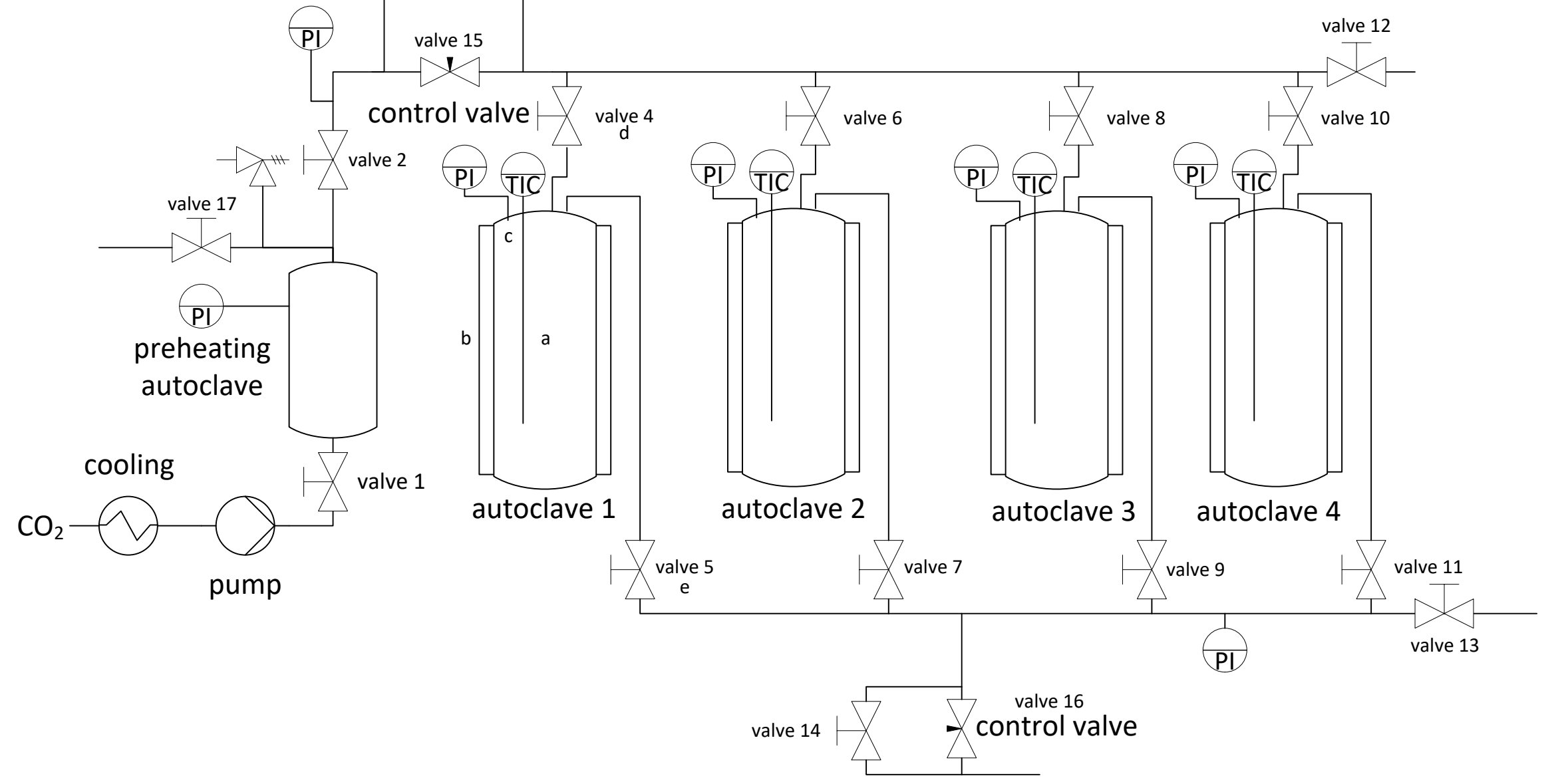

Figure 2: Scheme of the static supercritical $\mathrm{CO}_{2}$ impregnation plant to investigate the thermodynamic equilibrium using three $40 \mathrm{~mL}$ high pressure autoclaves. a: dip tube with temperature sensor, b: heating jacket, c: pressure indicator, $d$ : inlet valve, e: outlet valve. 


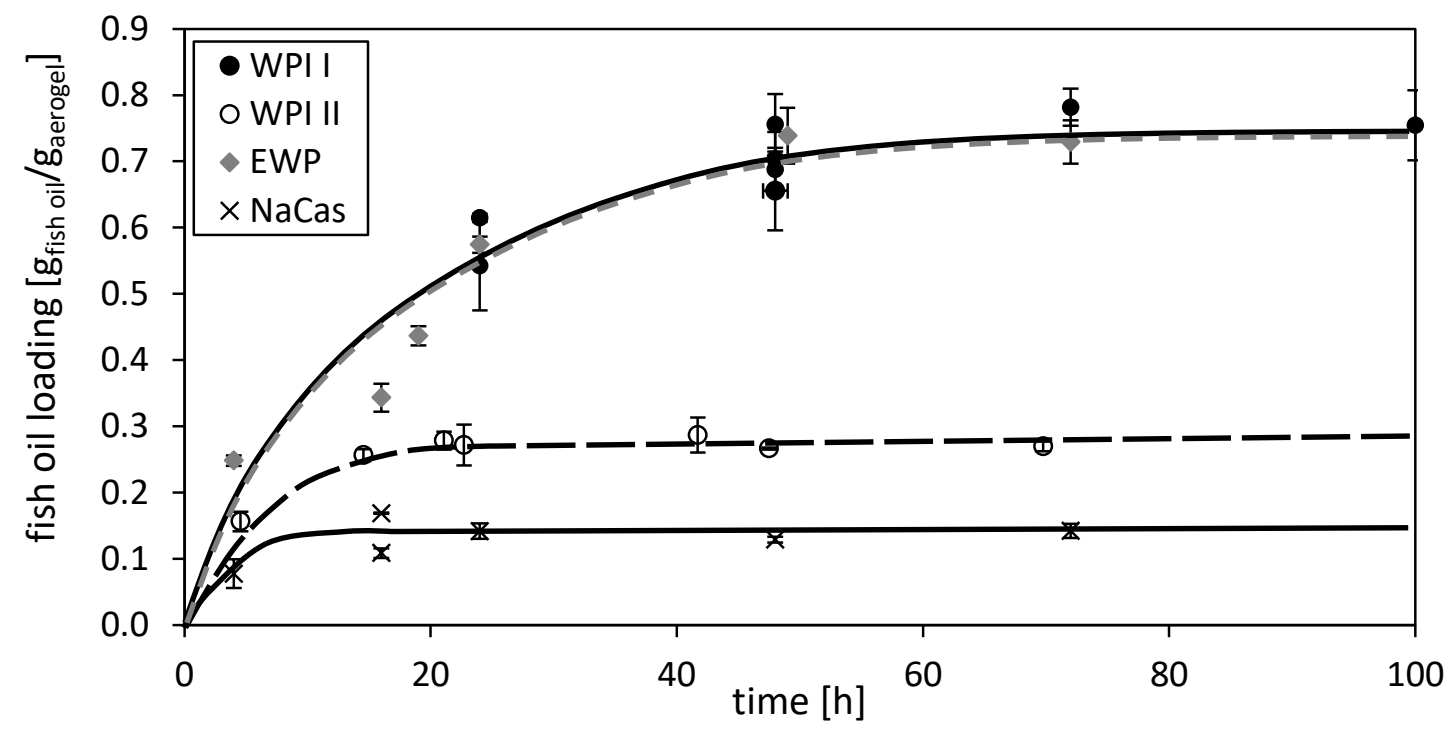

Figure 3: Adsorption kinetics of the fish oil from supercritical $\mathrm{CO}_{2}$ onto WPI-, EWP- and NaCasaerogel particles. Adsorption conditions: $P=18 \mathrm{MPa}, \mathrm{T}=313 \mathrm{~K}$. The lines are used to guide the eye (WPI I: black solid line, WPI II: black dashed line, EWP: grey dashed line, NaCas: black dotted line). 


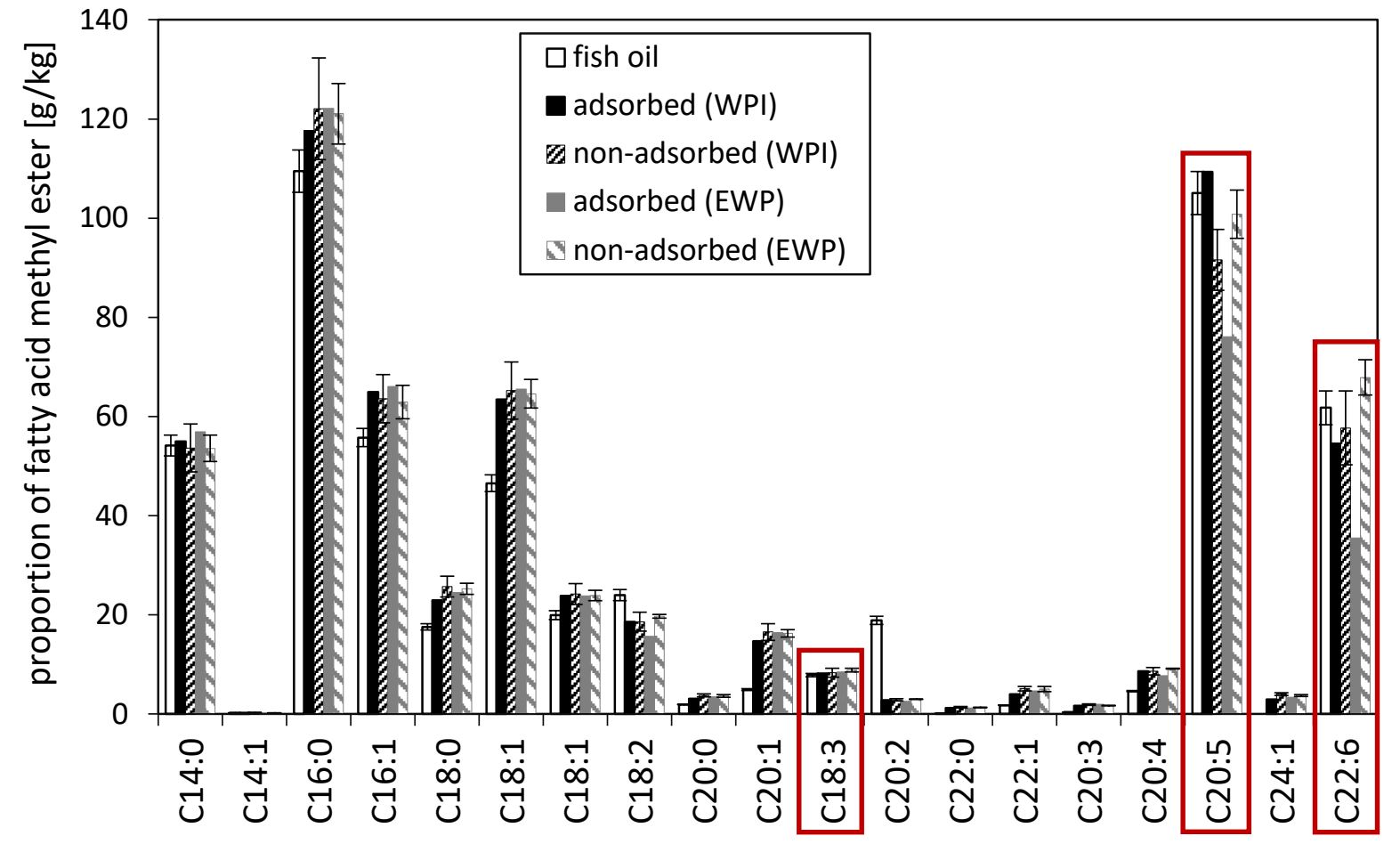

Figure 8: Fatty acid methyl ester distribution of the fresh fish oil, the adsorbed and non-adsorbed fish oil for WPI- and EWP-aerogels. Adsorption conditions: $P=18 \mathrm{MPa}, T=313 \mathrm{~K}, t \geq t_{\text {equilibrium }} \Omega$-3-fatty acids are marked in red. 


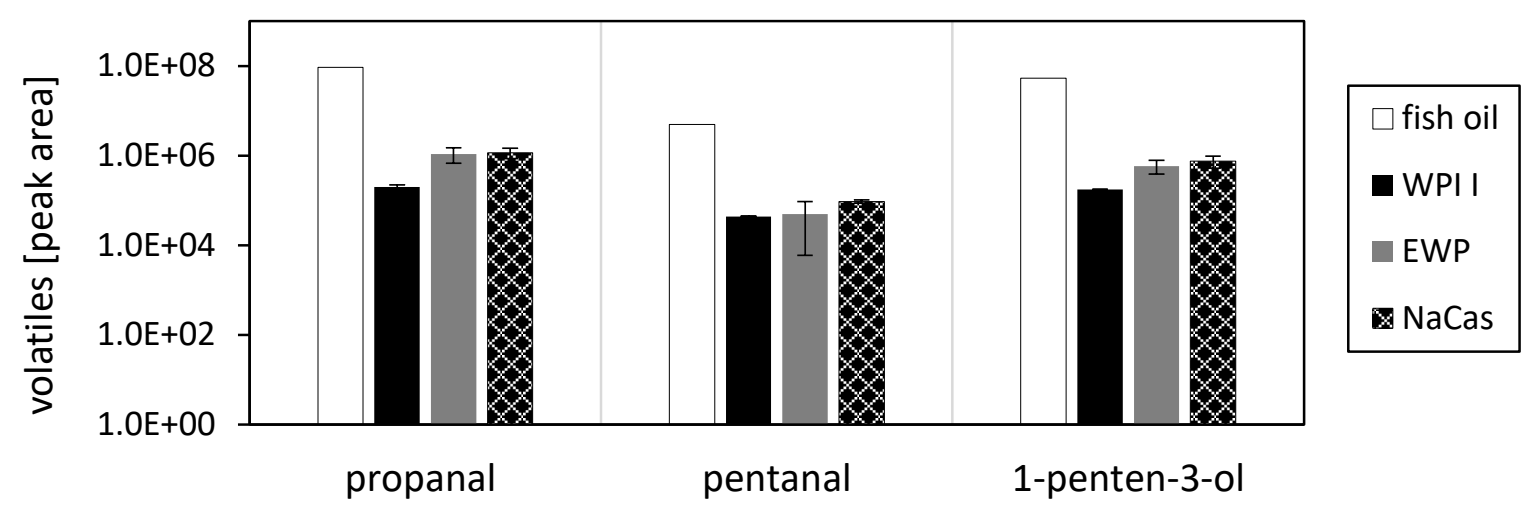

Figure 9: Volatiles propanal, pentanal and 1-penten-3-ol of pure fish oil and fish oil loaded WPI-, EWP- and NaCas-aerogel particles. The volatiles are related to $1 \mathrm{~g}$ fish oil. Adsorption conditions: $P=18 \mathrm{MPa}, T=313 \mathrm{~K}, \mathrm{t} \geq \mathrm{t}_{\text {equilibrium }}$. 


\section{List of figure captions}

\section{Encapsulation of fish oil in protein aerogel micro-particles}

Ilka Selmer ${ }^{* 1}$, Julia Karnetzke ${ }^{1}$, Christian Kleemann ${ }^{2}$, Mari Lehtonen ${ }^{3}$, Kirsi S. Mikkonen ${ }^{3,4}$, Ulrich Kulozik² $^{2}$, Irina Smirnova ${ }^{1}$

${ }^{1}$ Institute for Thermal Separation Processes, Hamburg University of Technology, Eißendorfer Straße 38, 21073 Hamburg (Germany), e-mail: ilka.selmer@tuhh.de, irina.smirnova@tuhh.de

${ }^{2}$ Technical University of Munich, Chair of Food and Bioprocess Engineering, Weihenstephaner Berg 1, 85354 Freising (Germany), e-mail: christian.kleemann@tum.de, ulrich.kulozik@tum.de

${ }^{3}$ Department of Food and Nutrition, University of Helsinki, P.O. Box 66, FIN-00014 Helsinki (Finland), mari.lehtonen@env.fi, kirsi.s.mikkonen@helsinki.fi

${ }^{4}$ Helsinki Institute of Sustainability Science, Faculty of Agriculture and Forestry, University of Helsinki, Finland

${ }^{*}$ corresponding author: Ilka Selmer

Figure 1: Scanning electron micrographs of utilized WPI-, EWP-, NaCas-aerogel particles (5 kV, magnification: 200 and 2000).

Figure 2: Scheme of the static supercritical $\mathrm{CO}_{2}$ impregnation plant to investigate the thermodynamic equilibrium using three $40 \mathrm{~mL}$ high pressure autoclaves. a: dip tube with temperature sensor, b: heating jacket, c: pressure indicator, d: inlet valve, e: outlet valve.

Figure 3: Adsorption kinetics of the fish oil from supercritical $\mathrm{CO}_{2}$ onto WPI-, EWP- and NaCas-aerogel particles. Adsorption conditions: $P=18 \mathrm{MPa}, \mathrm{T}=313 \mathrm{~K}$. The lines are used to guide the eye (WPI I: black solid line, WPI II: black dashed line, EWP: grey dashed line, NaCas: black dotted line).

Figure 4: Fish oil loading as function of the system pressure onto WPI-, EWP- and NaCas-aerogel particles. Adsorption conditions: $\mathrm{T}=313 \mathrm{~K}, \mathrm{t} \geq \mathrm{t}_{\text {equilibrium. }}$

Figure 5: Specific fish oil loading onto WPI-, EWP- and NaCas-aerogel particles related to the corresponding BET-surface area of the aerogel as function of the fish oil solubility in $\mathrm{CO}_{2}$ in comparison with the corresponding Freundlich isotherms (solid lines) and Langmuir isotherms (dashed lines). Adsorption conditions: $\mathrm{T}=313 \mathrm{~K}, \mathrm{t} \geq \mathrm{t}_{\text {equilibrium, }} 10 \mathrm{MPa}<\mathrm{P} 18.5 \mathrm{MPa}$.

Figure 6: Comparison of photographs taken with a light microscope of unloaded and fish oil loaded WPI-, EWP- and NaCas-aerogel particles (adsorption from supercritical $\mathrm{CO}_{2}$ and direct mixing with fish oil).

Figure 7: Composition of the fresh fish oil, the adsorbed and non-adsorbed fish oil for WPI-, EWP- and NaCasaerogels. Adsorption conditions: $P=18 \mathrm{MPa}, T=313 \mathrm{~K}, \mathrm{t}=48 \mathrm{~h}$. 
Figure 8: Fatty acid methyl ester distribution of the fresh fish oil, the adsorbed and non-adsorbed fish oil for

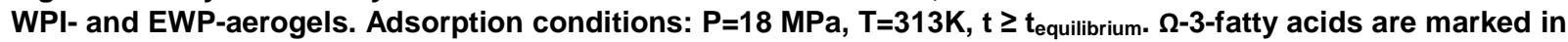
red.

Figure 9: Volatiles propanal, pentanal and 1-penten-3-ol of pure fish oil and fish oil loaded WPI-, EWP- and NaCas-aerogel particles. The volatiles are related to $1 \mathrm{~g}$ fish oil. Adsorption conditions: $P=18 \mathrm{MPa}, \mathrm{T}=313 \mathrm{~K}$, $t \geq t_{\text {equilibrium. }}$

Figure 10: Total volatiles without ethanol, total volatiles classified as oxidative markers for TGAs and the volatile ethanol for the utilized fish oil (stored at $3^{\circ} \mathrm{C}$ ), the non-adsorbed remaining fish oil in the autoclave, the unloaded aerogel particles and fish oil loaded aerogel particles. The volatiles were related to $0.5 \mathrm{~g}$ sample weight. Fish oil adsorption conditions: $P=18 \mathrm{MPa}, \mathrm{T}=313 \mathrm{~K}$.

Figure 11: Total volatiles without ethanol, total volatiles classified as oxidative markers for TGAs and the volatile ethanol for the fish oil, the remaining fish oil in the autoclave and fish oil loaded aerogel particles. The volatiles were related to $1 \mathrm{~g}$ fish oil. Fish oil adsorption conditions: $P=18 \mathrm{MPa}, \mathrm{T}=313 \mathrm{~K}$.

Figure 12: Sum of the volatiles propanal, pentanal and 1-penten-3-ol of fish oil loaded WPI I- and EWP-aerogel particles as function of the storage time. The volatiles are related to $\mathbf{1} \mathbf{g}$ fish oil. Fish oil adsorption conditions: $P=18 \mathrm{MPa}, \mathrm{T}=313 \mathrm{~K}$. Storage conditions: $\mathrm{T}=298 \mathrm{~K}$, humidity=0.11 $\mathrm{rH}$ (solid lines) and $0.33 \mathrm{rH}$ (dashed lines). 


\section{Highlights}

- Protein aerogel micro-particles were impregnated from supercritical $\mathrm{CO}_{2}$ solution

- Specific loadings up to $0.74 \mathrm{~g}$ fish oil $/ \mathrm{g}$ aerogel were achieved

- Fish oil loaded aerogel micro-particles showed free-flowing properties

- Fish oil composition and FAMEs could be maintained 